\title{
The Effect of Reference Price on Customers' Decisions in Online Shopping
}

\author{
Yihan Zheng ${ }^{1}$ \\ ${ }^{1}$ Mercersburg Academy, The United States \\ Correspondence: Yihan Zheng, Mercersburg Academy, The United States. E-mail: z12009@outlook.com
}

Received: September 3, 2019

Accepted: September 24, 2019 Online Published: September 25, 2019

doi:10.5539/ijps.v11n4p26

URL: https://doi.org/10.5539/ijps.v11n4p26

\begin{abstract}
In this research, we examined the effect that different reference prices have on online customers in their shopping process. We hypothesized that the actual price paid will be higher for participants who saw a higher reference price. We designed two different surveys targeting potential customers - the only difference between the two versions was the price for reference shown to the participants at the beginning of the survey. Designed to mimic the actual online shopping scenario, the surveys collected 136 responses in total, and the results suggest there is a difference of $\$ 22.93$ in the mean values of the price customers are willing to pay. The Hedges' $g$ value for the mean difference is 0.42 , which indicated that there is a practical significance. This result indicates that customers' willingness to pay will rise as the reference prices increase.
\end{abstract}

Keywords: behavioral economics, online shopping, reference prices

\section{Introduction}

Because of its incredible convenience, online shopping has significantly reshaped consumer behaviors in modern economies. The fields of psychology and behavioral economics have strived to understand the novel phenomena that have emerged as the internet has created a totally different environment from face-to-face communications, such as the newly formed concerns of consumers' privacy in online shopping (Miyazaki \& Fernandez, 2001). In addition, interest is growing in how existing concepts within these academic fields operate within the online context, such as the anchoring effect - defined as the phenomenon when individuals use certain values as a reference when evaluating unknown values even though those reference values may be irrelevant or misleading. In psychology, anchoring effect has long been seen as a power mechanism. It helps undermine judgements of individuals by providing an "anchor" for individuals to refer to. Numerous previous research has proven that anchoring effect occur in a variety of fields and scenarios (Bennett, 2014).

A number of studies have examined the role of the anchoring effect in consumer behaviors. For example, past studies have found that increases in the prices of irrelevant products that buyers encounter unintentionally would increase the price they are willing to pay (Nunes \& Boatwright, 2004). Dogerlioglu-Demir and Koçaş found similar results in products with relatively fixed internal values (Dogerlioglu-Demir \& Koçaş, 2015). In addition, scholars suggest that customers can be influenced by anchoring effects without realizing that their actions have been influenced by an anchor. Approaching the effect as an irrational decision making process, Wegener et al found out that the effect does not require elaborate thinking process (Wegener, Petty, Blankenship, \& Detweiler-Bedell, 2010). The study touched the irrational part of consumer psychology, and discovered surprising similarity between the irrational reactions and rational reactions toward same anchors. In all the aforementioned studies, however, consumers were only exposed to little information about the products other than the anchor. Either as vendors long the boardwalk (Nunes \& Boatwright, 2004), or restaurant ads (Dogerlioglu-Demir \& Koçaş, 2015), previous studies mostly touched only on scenarios where consumers were able to acquire limited knowledge of the products.

Research combining reference prices and online shopping scenarios has been rarely conducted. Unlike traditional shopping contexts, online shopping provides a unique platform where customers can quickly navigate to a multitude of sites with massive inventories. In fact, it turned out that convenience is the main factor that drives consumers to shop online (Chiang \& Dholakia, 2003) As a result of this convenience, compared to in-person shoppers, online shoppers are exposed to an immensely larger number of products, which allows customers to make broader parallel comparisons among similar products. It is possible that the differences 
between the online and in-person shopping context may influence how the anchoring effect operates. Specifically, because the anchoring effect depends upon the availability of information and online shoppers have greater access to information about how products are priced, the potency of the anchoring effect may differ in online shopping contexts. With more information and possibilities to compare similar products from different sellers, online shoppers are able to find the most economical option, thus weakening the effect anchor has on their willingness to pay. However, because online shoppers have limited time and energy to research on the products, the possibility that any costumers going through all possible shopping options and choosing the most economical one is rare, thus anchoring effect will still occur, as online shoppers do not have unlimited knowledge of the products.

The present research study was conducted with the intention of determining whether anchoring (or reference) pricing has effects on the consumers' willingness to pay when online shopping. We hypothesized that customers who view higher reference prices will be willing to pay higher prices when online shopping. This hypothesis aligns with findings from traditional shopping scenarios other than online shopping (e.g., Nunes \& Boatwright, 2004).

\section{Method}

\subsection{Participants}

136 participants were recruited through Amazon MTurk for this research. The only requirement for participation in the study was having an acceptance rate (i.e., the rate of acceptance from researchers of their previous responses at MTurk) above 80 percent to ensure the validity of their responses. All participants read a full-page consent for and consented to participate in the research study.

\subsection{Procedures}

To simulate the online shopping context, we designed an online survey that mimicked an actual shopping page containing iPhone 8 products as it would be presented on online marketplaces such as Amazon. The reason we chose iPhone 8 is that all products essentially were the same and there would not be any preferences based on certain features. Participants were given clear directions for completing the task, and right after the instructions the survey showed a reminder of the "official price" of the product on Apple website: "As you make the decision, keep in mind that the price of a 64GB iPhone 8 on official Apple website is [reference price]." The reminder was in bold and large font to be especially noticeable. The highlighted reference price varied across experimental conditions (i.e., \$680 and \$820) and was the only difference between conditions.

After viewing the reminder, participants saw a selection box similar to what would be present in the search result page on an online shopping website. Under each possible selection brief information was presented about the product and its price. Eight different iPhone 8 products with $256 \mathrm{~GB}$ were shown with purchase prices ranging from $\$ 559$ to $\$ 749$. The purchase price that the participant selected collected as the dependent variable used in subsequent analyses (i.e., willingness to pay). Notably, the mean purchase prices of the products listed was $\$ 627.90$, significantly lower than the reference prince in both of the experimental conditions.

SurveyMonkey was used to generate the survey, and the data was collected through Amazon MTurk. Participants received $\$ 1.00$ for completing the survey. Participants completed a thorough informed consent process. We also included a survey code at the end of the survey for the participants to fill in at the MTurk platform to address the possibility that participants would rush through the survey to receive payment. The survey code effectively prevented this from happening and allowed us to filter out the participants who did not finish the survey as attentively as they should. Overall, these procedures ensured the quality of the data used in subsequent analyses.

\subsection{Design and Analytic Approach}

The experiment was a $1 \times 2$ experimental design in which we investigated the effect of reference price on customer's final purchasing price. Here, the reference price was the independent variable, and it had two levels: $\$ 680$ and $\$ 820$. We used an independent $t$-test to determine the statistical significance between the mean values of the two experimental conditions.

\section{Results}

There were 136 responses collected in total, 61 for the higher reference price group and 75 for the lower reference price group. Our hypothesis was that there would be a significant increase of the willingness to pay in the higher reference group compared to the lower reference group. 
The result of data supported our hypothesis: the purchase prices participants chose were higher in the higher reference price group. We note that because the purchase prices did not include every possible dollar amount, the dollar amount selected in participants' responses did not necessarily equal their exact willingness to pay. However, the available purchase prices participants selected from was sufficiently broad and graduated to capture variation, thus indicating this measure is adequate to detect an anchoring effect. Customers' willingness to pay is higher when they were informed that the "official price" was $\$ 820(M=615.77, S D=63.67)$ than when they were informed that the "official price" was $\$ 680(M=592.84, S D=27.18)$. Running the independent $t$-test, the $t$-value for the data set is 2.41 , and the $p=0.001$, which offered strong evidence that there is a statistically significant difference in the means of the two experimental conditions (see Table 1).

Table 1. Descriptive Statistics and Analytic Results

\begin{tabular}{cccc}
\hline & $\begin{array}{c}\text { Number of } \\
\text { observations }\end{array}$ & Mean value & $\begin{array}{c}\text { Standard } \\
\text { Deviation }\end{array}$ \\
\cline { 2 - 4 } High-reference price group & 61 & 615.77 & 63.67 \\
Low-reference price group & 75 & 592.84 & 47.18 \\
Difference & - & $22.93^{* *}$ & - \\
\cline { 2 - 4 } & & &
\end{tabular}

\section{Discussion}

The statistically significant difference of over $\$ 20$ in mean purchasing price (i.e., Hedges' $g=0.42$ ) supports our hypothesis that customers' willingness to pay will increase as the reference prices increase. It appears that when the reference price was higher, the produced anchoring effect (i.e., the effect of people using irrelevant data for reference in their decisions) subconsciously influenced participants' decision making process, and the price they were willing to pay also increased. Compare to previous similar experiments done in traditional shopping scenarios, anchoring effect appears to be slightly weaker.

Building from past studies in other shopping contexts (e.g., Nunes and Boatwright, 2004), the present research study supports the presence of an anchoring effect in the context of online shopping. The results indicate that such an effect was functioning even when the customers had the opportunity to obtain full information of the products to choose. While in traditional shopping scenarios, customers are only aware of limited information of the products and other choices, in online shopping customers have a much better understanding of all similar products in the market. While all participants had easy access to the price information of all the products listed, not all of them made the most economical choice. Instead, the anchoring price still had a significant effect. It is noteworthy that in the experiment only seven different products were shown, thus it cost virtually no extra time or energy to gather information of all products, which theoretically would weaken the anchoring effect. However, the anchoring effect still appears to have its impact. Furthermore, it appears that even if customers realized the anchoring prices were way too high (i.e., the $\$ 820$ group, whose anchoring price was higher than any of the actual prices listed) they still subconsciously raised their target prices. After seeing the price information of all the products listed, the $\$ 820$ group likely realized that the anchoring price was much higher than the prices of all the products listed; thus, logically speaking, it no longer served as a reference for proper prices. However, this piece of seemingly useless information still made a considerable difference in their decision making process and raised the actual prices they were willing to pay.

Future research should focus on other factors that could influence the effectiveness of the anchoring effect. Because there was only one independent variable and two levels, more sophisticated analysis was limited in this research. However, future research could take more factors into consideration, such as how these results might vary across customers' age, gender, and education background; questions of moderation across these demographic variables could not be addressed in the present study because these demographic data were not collected due to the privacy policy of the MTurk platform. For example, younger customers may be more savvy in processing the larger quantity of information, which could further weakening the effectiveness of anchoring. Overall, the study's original hypothesis was supported; in the online context, the actual prices customers were willing to pay was higher when the anchoring price was higher. 


\section{References}

Bennett, M. B. (2014). Confronting Cognitive "Anchoring Effect" and "Blind Spot" Biases in Federal Sentencing: a Modest Solution for Reforming a Fundamental Flaw. The Journal of Criminal Law and Criminology, 104, 489-534. Retrieved from JSTOR database.

Chiang, K.-P. \& Dholakia, R. R. (2003). Factors Driving Consumer Intention to Shop Online: An Empirical Investigation. Journal of Consumer Psychology, 13, 177-183. https://doi.org/10.1207/153276603768344898

Dogerlioglu-Demir, K. \& Koçaş, K. (2015). Seemingly incidental anchoring: The effect of incidental environmental anchors on consumers' willingness to pay. Marketing Letters, 26, 607-618. https://doi.org/10.1007/s11002-014-9295-0

Miyazaki, A. D. \& Fernandez, A. (2001). Consumer perceptions of privacy and security risks for online shopping. Journal of Consumer affairs, 35(1), 27-44. https://doi.org/10.1111/j.1745-6606.2001.tb00101.x

Nunes, J. C. \& Boatwright, P. (2004). Incidental prices and their effect on willingness to pay. Journal of Marketing Research, 41(4), 457-466. https://doi.org/10.1509/jmkr.41.4.457.47014

Wegener, D. T., Petty, R. E., Blankenship, K. L. \& Detweiler-Bedell, B. (2010). Elaboration and numerical anchoring: Implications of attitude theories for consumer judgment and decision making. Journal of Consumer Psychology, 20(1), 5-16. https://doi.org/10.1016/j.jcps.2009.12.003

\section{Copyrights}

Copyright for this article is retained by the author(s), with first publication rights granted to the journal.

This is an open-access article distributed under the terms and conditions of the Creative Commons Attribution license (http://creativecommons.org/licenses/by/4.0/). 